\title{
Colaboração: uma ação para legitimar as pesquisas da própria prática de professores de matemática
}

Patrícia Sandalo Pereira*

Edinalva Teixeira da Cruz Sakai**

Kely Fabrícia Pereira Nogueira***

*(Universidade Federal de Mato Grosso do Sul - UFMS, Campo Grande, Mato Grosso do Sul, Brasil)

**(Universidade Federal de Mato Grosso do Sul - UFMS, Campo Grande, Mato Grosso do Sul, Brasil)

***(Universidade Federal de Mato Grosso do Sul - UFMS, Campo Grande, Mato Grosso do Sul, Brasil)
Resumo: Este artigo tem como objetivo apresentar uma síntese da estrutura teórico-metodológica que sustenta as dissertações e as teses produzidas entre 2001 e 2016, envolvendo a pesquisa da própria prática, e que possuem a colaboração como uma das ações para a legitimação do processo investigativo. O caminhar metodológico possui características da pesquisa colaborativa, com o subsídio dos estudos bibliográficos. A análise dos dados revelou que, embora o termo "própria prática" esteja presente nas pesquisas, ainda são poucas as produções nas quais as ações para a legitimação do processo configuram-se como colaboração.

Palavras-chave: Educação matemática. Pesquisa da própria prática. Colaboração. 


\section{INTRODUÇÃO}

0 ato de ensinar é uma prática social complexa, característica da atividade do professor. Compreendemos que a sociedade brasileira contemporânea, mediante as rápidas transformações, exige novas posturas, conhecimentos e fazeres dos professores. Por outro lado, entendemos que esse contexto, por vezes, é contraditório, carregado de conflitos de ideias, culturas e interpretações, que exige um posicionamento do professor. Logo, ser professor requer

[...] saberes e conhecimentos científicos, pedagógicos, educacionais, sensibilidade de experiências, indagações teóricas e criatividade para fazer frente às situações únicas, ambíguas, incertas, conflitivas e, por vezes, violentas, das situações de ensino, nos contextos escolares e não escolares (CHARLOT, 2014, p. 9).

Mediante essas ponderações, consideramos que essa multiplicidade de natureza inerente à prática do professor necessita de maneira contundente estar associada à mediação reflexiva e crítica em face da formação humana dos alunos e das transformações sociais concretas, questionando-se os modos de pensar, sentir, agir, de produzir e difundir conhecimento na sociedade.

Partindo desse entendimento, no campo da educação matemática observamos, a partir das pesquisas já produzidas, seja em artigos, teses e dissertações, um crescente empenho dos professores de matemática em refletir sobre as relações de ensino e aprendizagem que ocorrem em suas salas de aula. Explicitamos que esse processo de reflexão é cíclico, visto que somos sujeitos sociais e relacionais e, a partir do outro ou dos outros, podemos encontrar pontos de confronto para a reconstituição de nossas práticas.

Nesse sentido, como alternativas para a compreensão dessas relações, professores de diferentes níveis de ensino têm se voltado aos processos de pesquisa e formação, nos mais diversos contextos: escolas, instituições de ensino superior, programas de pós-graduação, grupos de estudos, dentre outros. Charlot (2014, p. 9) aponta-nos que o professor só amplia a sua consciência sobre a própria prática quando é confrontado, na medida em que "[...] impõem-se rever suas práticas e as teorias que as informam, pesquisando a prática e produzindo novos conhecimentos para a teoria e a prática de ensinar”. Ponte (2004) chama a atenção para as questões que afetam diretamente a prática dos professores, visto que somos seres em formação constante, suscetíveis a uma infinidade de necessidades inerentes aos sujeitos sociais. Assim sendo, no processo de ensino e aprendizagem é 
preciso considerar alguns problemas explícitos na área educacional.

\begin{abstract}
[...] o insucesso de seus alunos, relativamente a objectivos de aprendizagem curricular e até objectivos básicos de socialização e enculturação; a desadequação dos currículos e programas em relação às necessidades e condições dos públicos a que se destinam; o modo ineficaz e desgastante como funcionam as instituições educativas; a incompreensão de grande parte da sociedade, a começar pelos meios de comunicação social, para as condições extremamente adversas em que se trabalha na educação (PONTE, 2004, p. 38).
\end{abstract}

Diante desse panorama, muito desses profissionais têm buscado cada vez mais investigar de maneira sistemática os problemas que surgem nos mais variados contextos de sua atuação, culminando, por vezes, na investigação de sua própria prática. Nesta vertente, Alarcão $(2001$, p. 5) enfatiza que não consegue conceber

\begin{abstract}
[...] um professor que não se questione sobre as razões subjacentes às suas decisões educativas, que não se questione perante o insucesso de alguns alunos, que não faça dos seus planos de aula meras hipóteses de trabalho a confirmar ou infirmar no laboratório que é a sala de aula, que não leia criticamente os manuais ou as propostas didácticas que lhe são feitas, que não se questione sobre as funções da escola e sobre se elas estão a ser realizadas.
\end{abstract}

No entanto, ao pensar na constituição de uma investigação dessa natureza, surgem-nos alguns questionamentos: como se dá o desenvolvimento dessas pesquisas? Que estruturas teóricas e/ou metodológicas apresentam? Quais contribuições uma pesquisa sobre a própria prática pode proporcionar ao professor investigador e/ou ao contexto em que a sua prática acontece? Assim, instigados por essas e tantas outras indagações, desenvolvemos este estudo.

Vale dizer que o estudo em questão tratou de um levantamento bibliográfico, cuja origem deu-se por meio da nossa participação no Projeto Universal elaborado e submetido ao CNPq pelo Grupo de Estudos e Pesquisas sobre a Formação de Professores de Matemática (GEPFPM), com início no ano de 2013 e conclusão em 2016, sob a coordenação geral do prof. dr. Dario Fiorentini (FE/Unicamp). 0 projeto intitulado Mapeamento e estado da arte da pesquisa brasileira sobre o professor que ensina matemática ${ }^{1}$ teve como objetivo principal mapear, descrever e sistematizar as pesquisas brasileiras,

FIORENTINI, D.; PASSOS, C. L. B.; LIMA, R. C. R. (Org.) Mapeamento da pesquisa acadêmica brasileira sobre o professor que ensina matemática: período 2001-2012. FEUnicamp: Campinas, E-book, 2016. Disponível em: 〈https://www.fe.unicamp.br/pf-fe/ pagina_basica/58/e-book-mapeamento-pesquisa-pem.pdf $>$. 
cujo estudo centrava-se no professor que ensina matemática, produzidas no âmbito dos programas de pós-graduação stricto sensu das áreas de Educação e Ensino da Coordenação de Aperfeiçoamento de Pessoal de Nível Superior (Capes), no período entre 2001 e 2012.

Envolvidos nesse processo investigativo - que, em um pouco mais de uma década, identificou, entre dissertações e teses, 858 pesquisas que versam, nos mais variados aspectos, sobre o professor que ensina matemática -, voltamo-nos para a pesquisa da própria prática por ser uma temática que, ao mesmo tempo que se apresenta emergente no contexto acadêmico, é, intuitivamente, inerente ao fazer do professor. Para tanto, tomamos como base o corpus de estudo constituído por meio do projeto já mencionado e avançamos em nossa busca por mais quatro anos, ou seja, o período de 2013 a 2016, totalizando 16 pesquisas.

Assim, este artigo tem como objetivo apresentar uma síntese da estrutura teórico-metodológica que sustenta as dissertações e teses produzidas de 2001 a 2016, envolvendo as pesquisas da própria prática que possuem a colaboração como uma das ações para a legitimação do processo investigativo.

\section{CARACTERIZANDO A PESQUISA DA PRÓPRIA PRÁTICA}

$O$ ato de ensino e aprendizagem não é unicamente um encontro entre os sujeitos (professor e aluno). Para além disso, é um processo antropológico que embasa a especificidade da espécie humana (CHARLOT, 2014). Partindo desse entendimento, compreendemos que a complexidade torna-se inerente à natureza da prática docente, de modo que a educação no sentido macro não é somente a humanização, mas também a socialização. Dessa forma, o ato de ensinar e aprender depende dos sujeitos envolvidos, das estruturas e das relações sociais.

Assim, professores conscientes que buscam aprimorar-se não somente na sua área, mas como um todo social, partem de suas próprias indagações e reflexões mediadas por suas práticas. Eles permitem-se olhar-se e debruçarse em si mesmos. Não mais olhar e confrontar o outro, as práticas dos outros, mas as suas próprias práticas no viés do confronto para a transformação.

Destarte, mediante essas ponderações, faz-se necessário recorrermos a pesquisa e formação, na busca por compreender e transformar as nossas práticas. Por outro lado, de que maneira essa prática influencia e/ou é influenciada pelos contextos da realidade objetiva? Desses e de tantos outros 
questionamentos, tem despontado o gênero de pesquisa² denominado pesquisa da própria prática (PONTE, 2008).

Adjetivamos, neste texto, os profissionais do magistério que investigam a sua própria prática como “professor investigador”. Nessa concepção, o professor investigador é aquele que realiza investigação sobre a sua própria prática, não apenas relacionada com o aluno e a aprendizagem, restrito aos problemas pedagógicos que geram ações particulares em suas salas de aula, mas também ao investigar outros aspectos que direta ou indiretamente exercem influência em sua prática, uma vez que esse professor pode também tomar como ponto de partida para a sua investigação o contexto social, cultural e político, em toda a complexidade na qual a sua ação educativa se insere. Nessa perspectiva, Ponte (2002, p. 10) ressalta que a pesquisa da própria prática "deve emergir como um processo genuíno dos actores envolvidos, em busca do desenvolvimento do seu conhecimento, procurando solução para os problemas com que se defrontam e afirmando assim a sua identidade profissional".

Segundo o autor, essa forma de investigação possui uma característica definidora que a distingue das outras pesquisas sobre professores, tendo em vista que, nessa modalidade, o investigador estuda não um objeto qualquer, mas aspectos intrínsecos a sua própria prática docente, evidenciando dois tipos de objetivos: alterar algum aspecto da prática (intervir e transformar), uma vez estabelecida a necessidade de mudanças; e compreender a natureza dos problemas que afetam essas mesmas práticas, com vistas à definição de estratégias de ação.

Portanto, vale dizer que a pesquisa da própria prática é justificável na medida em que os problemas emergentes da prática docente em seus diversos níveis requerem do professor - para além do simples bom senso e boa vontade - capacidades de problematização e investigação, formação contínua e desenvolvimento profissional.

No Brasil, a pesquisa da própria prática é recente e ainda pouco reconhecida como um gênero de pesquisa. Os primeiros trabalhos desenvolvidos nessa perspectiva por um professor que ensina matemática, na área de Educação Matemática no Brasil, foi o de Castro (2004), intitulado: Um estudo sobre a própria prática em um contexto de aulas investigativas de Matemática, orientado pelo prof. dr. Dario Fiorentini (Unicamp/FE), e o de Almeida (2004), intitulado: Trabalhando matemática financeira em uma sala de

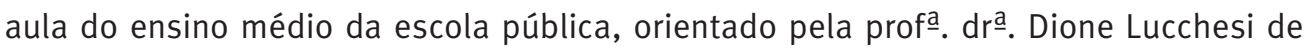
Carvalho (FE/Unicamp). 
Day (2001, p. 21) compreende que o desenvolvimento profissional dos professores é “[...] o processo através do qual os professores, enquanto agentes de mudança, revêem, renovam e ampliam, individualmente ou colectivamente, o seu compromisso com os propósitos morais do ensino", desenvolvendo, de forma mediada e crítica, conhecimentos e habilidades. Nos estudos de Ponte (1998, p. 38), podemos observar que um dos aspectos mais importantes da noção de desenvolvimento profissional é a articulação entre os níveis individual e coletivo “[...] onde o professor tem oportunidade de interagir com outros e sentir-se apoiado, onde pode conferir as suas experiências e recolher informações importantes”. Partindo dessa articulação, o autor esclarece-nos que o conhecimento gerado pelos professores em uma investigação sobre a sua prática pode gerar ações formativas tanto para o professor envolvido como também para o contexto sociopolítico em que essas ações acontecem.

\section{AÇÃO COLABORATIVA}

A colaboração entre professores (BOAVIDA; PONTE, 2002; PONTE; SERRAZINA, 2003) pode ser considerada como uma estratégia de grande utilidade para 0 enfrentamento dos problemas ou dificuldades que surgem frequentemente no campo das práticas docentes, especialmente aqueles que não são fáceis ou viáveis de resolver de modo puramente individual. Desse modo, as ponderações evidenciadas remetem-nos a outro importante aspecto da pesquisa da própria prática - o seu desenvolvimento em processos de colaboração. Tais processos valorizam, discutem e apropriam-se dos resultados e/ou contribuições que essas pesquisas produzem.

Temos visto, nos últimos tempos, mais precisamente na última década, o despontar do termo colaboração, seja nas pesquisas desenvolvidas no âmbito dos programas de pós-graduação ou em contextos de formação docente. Os estudos de Ibiapina (2008, 2009), Liberali (2009), Magalhães (2009), entre outros, vêm apontando para uma nova concepção de pesquisa, a pesquisa colaborativa, que alia, ao mesmo tempo, a produção de conhecimentos e 0 desenvolvimento profissional de pesquisadores e docentes, assinalando para uma aproximação entre o mundo da pesquisa e o mundo escolar.

Dessa forma, forjada em uma dupla identidade, ou seja, pesquisa e formação, a pesquisa colaborativa distinguiu-se de outras modalidades pelo seu caráter participativo, colaborativo e reflexivo. Ferreira e Ibiapina (2011) deixam claro essas particularidades ao afirmarem que 
[...] o foco da Pesquisa Colaborativa é a vida real do professorado, bem como do processo educativo e as relações estabelecidas pelos professores e pesquisadores como sujeitos da história que constroem no desenvolvimento da atividade docente, tornando-os mais conscientes do contexto no qual estão inseridos, alicerçados por visão e compreensão crítica das suas atuações. Por conseguinte, pesquisar, na proposta colaborativa, implica refletir sobre o agir e sobre as teorias que lhe servem de esteio, como também criar formas de interpretá-los e transformá-los (FERREIRA; IBIAPINA, 2011, p. 122, grifo nosso).

Para além de uma aproximação e mediação entre a comunidade de pesquisa e a comunidade escolar, a abordagem colaborativa requer, nesse processo, a partir dos pontos de vista de seus partícipes e das reflexões críticas sobre a sua prática,

[...] mudar o sistema de relações entre pesquisador e pesquisado com posturas que visam criar condições para pesquisadores e professores trabalharem de forma compartilhada e, conjuntamente, compreenderem e transformarem o agir e a teoria que fundamente a atividade docente (FERREIRA; IBIAPINA, 2011, p. 122).

No contexto da pesquisa da própria prática, que se alia aos processos colaborativos, podemos citar os trabalhos desenvolvidos pelo Grupo de Trabalho de Investigação (GTI) da Associação de Professores da Matemática (APM) de Portugal. Em 2002, o grupo apresentou uma síntese das suas ações formativas no livro intitulado Reflectir e investigar sobre a prática profissional (GTI, 2002). Os trabalhos apresentados nessa obra reafirmam a concepção de que investigar é um processo privilegiado de construção e apropriação do conhecimento, quer seja de forma individual ou de forma coletiva. Entendem que a pesquisa da própria prática pode ser considerada como uma atividade que possibilita esse processo, agregando grande valor formativo para os professores que se envolvem ativamente nela. Ademais, a literatura existente indica que a promoção desses processos, quando associados às dinâmicas práticas e sociais, e aliados aos interesses e necessidades do seu contexto profissional, concorre para um progressivo desenvolvimento das potencialidades e construção de novos conhecimentos e de novas práticas.

Dessa forma, desenvolvidas nessa vertente, é possível afirmar que as pesquisas da própria prática não constituem apenas um trabalho teóricoprático, mas também um trabalho social e político. Pode-se afirmar que isso deriva dos processos colaborativos, os quais pressupõem negociações cuidadosas, tomada coletiva de decisões, comunicação, diálogo e aprendizagem por parte de todos os envolvidos. Logo, assumir a investigação da própria prática em processos de colaboração significa que professores e futuros professores estarão trabalhando conjuntamente na perspectiva de 
gerar conhecimento, visando à reflexão e à (re)construção de sua própria prática. Assim, no intuito de compreender a estrutura teórico-metodológica de uma pesquisa, que vise investigar a própria prática apoiada em processos de colaboração, desenvolvemos este estudo.

\section{Metodologia de inVestigaçÃo}

A abordagem metodológica adotada inscreve-se no campo dos estudos bibliográficos que, segundo Vosgerau e Romanowski (2014), são aqueles que preferencialmente fazem-se a partir de documentação escrita, possibilitando o contato com o que já se produziu e registrou a respeito de determinado tema. Nesse tipo de estudo, os encontros com outras pesquisas são mediados por levantamentos, mapeamentos e fichamentos das leituras.

Assim, no intuito de responder ao nosso objetivo, partimos do corpus maior (2001 -2012), composto por 858 pesquisas que tiveram como foco de estudo o professor que ensina matemática (PEM), e iniciamos um processo de mapeamento em busca de pesquisas que se tratassem, em essência, de pesquisas da própria prática.

Vale ressaltar que, durante os procedimentos de buscas, identificamos inúmeras pesquisas que citam o termo própria prática, porém, a partir de uma leitura mais cuidadosa, foi possível perceber que, embora o uso do termo fosse bastante frequente, elas não se configuravam em uma pesquisa da própria prática. Notamos que, na maioria dos casos em que o termo própria prática era citado, o pesquisador estava em busca da análise e/ou compreensão da prática de outrem, em relação a um conteúdo específico, ou ainda, em alguns casos, sendo participante da pesquisa, porém sem colocar a sua própria prática como foco de estudo.

Assim, compreendidas essas especificidades, finalizamos nossas buscas e, como resultado do primeiro mapeamento (entre 2001 e 2012), foi possível identificar 14 pesquisas. Posteriormente, acrescentamos mais duas pesquisas originárias de uma nova busca, no período entre 2013 e 2016, constituindo um novo corpus de estudo composto por 16 produções, descritas no Quadro 1. 
Quadro 1 - Pesquisas da própria prática

\begin{tabular}{|c|c|c|c|c|}
\hline Autor & Título & Nível & Instituição & $\begin{array}{l}\text { Ano de } \\
\text { defesa }\end{array}$ \\
\hline $\begin{array}{l}\text { CASTRO, } \\
\text { Juliana } \\
\text { Facanali }\end{array}$ & $\begin{array}{c}\text { Um estudo sobre a própria prática em } \\
\text { um contexto de aulas investigativas de } \\
\text { matemática }\end{array}$ & Mestrado & Unicamp & 2004 \\
\hline $\begin{array}{l}\text { ALMEIDA, } \\
\text { Adriana } \\
\text { Correa }\end{array}$ & $\begin{array}{c}\text { Trabalhando matemática financeira em uma } \\
\text { sala de aula do ensino médio da escola } \\
\text { pública }\end{array}$ & Mestrado & Unicamp & 2004 \\
\hline $\begin{array}{l}\text { MACHADO } \\
\text { JUNIOR, } \\
\text { Arthur } \\
\text { Gonçalve } \\
\end{array}$ & $\begin{array}{l}\text { Modelagem matemática no ensino- } \\
\text { aprendizagem: ação e resultados }\end{array}$ & Mestrado & UFPA & 2005 \\
\hline $\begin{array}{c}\text { LIMA, } \\
\text { Claudia } \\
\text { Neves do } \\
\text { Monte Freitas } \\
\text { de } \\
\end{array}$ & $\begin{array}{l}\text { Investigação da própria prática docente } \\
\text { utilizando tarefas exploratório-investigativas } \\
\text { em um ambiente de comunicação de ideias } \\
\text { matemáticas no ensino médio }\end{array}$ & Mestrado & USF & 2006 \\
\hline $\begin{array}{l}\text { BIAJONE, } \\
\text { Jefferson }\end{array}$ & $\begin{array}{c}\text { Trabalho de projetos: possibilidades } \\
\text { e desafios na formação estatística do } \\
\text { pedagogo }\end{array}$ & Mestrado & Unicamp & 2006 \\
\hline $\begin{array}{l}\text { BITENCOURT, } \\
\text { Karliúza } \\
\text { Fonseca }\end{array}$ & $\begin{array}{c}\text { Educação matemática por projetos: } \\
\text { perspectivas e prática pedagógica no } \\
\text { contexto escolar }\end{array}$ & Mestrado & UFRGS & 2007 \\
\hline $\begin{array}{l}\text { LOPES, } \\
\text { Maria da } \\
\text { Penha } \\
\end{array}$ & $\begin{array}{c}\text { Desvelando práticas bem-sucedidas de uma } \\
\text { professora de matemática }\end{array}$ & Doutorado & UFMG & 2007 \\
\hline $\begin{array}{l}\text { FONSECA, } \\
\text { Rosana Carla }\end{array}$ & $\begin{array}{c}\text { Matemática se aprende brincando?! Jogos } \\
\text { eletrônicos como uma possibilidade de } \\
\text { ensino }\end{array}$ & Mestrado & Umesp & 2007 \\
\hline $\begin{array}{l}\text { ABREU, } \\
\text { Maria das } \\
\text { Graças dos } \\
\text { Santos } \\
\end{array}$ & $\begin{array}{c}\text { Uma investigação sobre a prática } \\
\text { pedagógica: refletindo sobre a investigação } \\
\text { nas aulas de matemática }\end{array}$ & Mestrado & UFSCAR & 2008 \\
\hline $\begin{array}{l}\text { ARAGÓN, } \\
\text { Dionara } \\
\text { Teresinha da } \\
\text { Rosa } \\
\end{array}$ & $\begin{array}{l}\text { Formação continuada de professores de } \\
\text { matemática: espaço de possibilidades para } \\
\text { produzir formas de resistência docente }\end{array}$ & Mestrado & UFRGS & 2009 \\
\hline $\begin{array}{l}\text { FELIX, } \\
\text { Thiago } \\
\text { Francisco }\end{array}$ & $\begin{array}{c}\text { Pesquisando a melhoria de aulas de } \\
\text { matemática segundo a proposta curricular } \\
\text { do estado de São Paulo, com a metodologia } \\
\text { da pesquisa de aula (Lesson Study) }\end{array}$ & Mestrado & UFSCAR & 2010 \\
\hline $\begin{array}{c}\text { LIMA, } \\
\text { Cristina } \\
\text { Maria Peixoto } \\
\text { Berbert }\end{array}$ & $\begin{array}{c}\text { Trajetórias no chão da escola: uma pedagoga } \\
\text { nas trilhas da educação matemática com } \\
\text { professores de séries iniciais }\end{array}$ & Mestrado & UFPR & 2010 \\
\hline
\end{tabular}




\begin{tabular}{|c|c|c|c|c|}
\hline $\begin{array}{c}\text { FERNANDES, } \\
\begin{array}{c}\text { Fernando } \\
\text { LuÍs Pereira }\end{array}\end{array}$ & $\begin{array}{c}\text { Iniciação e práticas de letramento algébrico } \\
\text { em aulas exploratório-investigativas }\end{array}$ & Mestrado & Unicamp & 2011 \\
\hline $\begin{array}{c}\text { MESQUITA, } \\
\text { Flávio } \\
\text { Nazareno } \\
\text { Araujo }\end{array}$ & $\begin{array}{c}\text { As dinâmicas praxeológicas e cognitivas e } \\
\text { a construção do conhecimento didático do } \\
\text { professor de matemática }\end{array}$ & Mestrado & UFPA & 2011 \\
\hline $\begin{array}{c}\text { QUISBERT, } \\
\text { Susan Quiles }\end{array}$ & $\begin{array}{c}\text { Relações de uma professora pesquisadora } \\
\text { de sua própria prática com o uso de } \\
\text { materiais didáticos institucionais de } \\
\text { matemática }\end{array}$ & Mestrado & Unicsul & 2015 \\
\hline $\begin{array}{c}\text { MILANI, } \\
\text { Camille } \\
\text { Bordin Botke }\end{array}$ & $\begin{array}{c}\text { O deóriconvolvimento do pensamento } \\
\text { matemática no processo educativo }\end{array}$ & Mestrado & UFPR & 2016 \\
\hline
\end{tabular}

Fonte: E-Book: 〈https://www.fe.unicamp.br/pf-fe/pagina_basica/58/e-book-mapeamento-pesquisapem.pdf〉 e banco de teses da Capes: 〈http://catalogodeteses.capes.gov.br〉.

Como podemos observar na sistematização apresentada anteriormente, foram identificadas 16 pesquisas, sendo uma tese de doutorado e 15 dissertações de mestrado acadêmico, que tiveram como sujeito protagonista da investigação o próprio pesquisador, e como objeto de pesquisa, a sua própria prática.

No entanto, nosso objetivo é olhar para as pesquisas que foram desenvolvidas mediadas por ações colaborativas. Sendo assim, foi necessária a aplicação de um novo mapeamento.

Dessa forma, a partir das leituras e dos fichamentos das produções do Quadro 1 , foi possível identificar apenas duas pesquisas que mais se aproximaram do processo colaborativo, o qual nos descrevem Boavida e Ponte (2002), e Ferreira e Ibiapina (2011). São elas: Castro (2004) e Quisbert (2015).

O Quadro 2 apresenta uma síntese da estrutura metodológica dessas duas pesquisas. 
Quadro 2: síntese da estrutura metodológica dessas duas pesquisas.

\begin{tabular}{|c|c|c|c|}
\hline $\begin{array}{l}\text { Autor/ } \\
\text { Ano }\end{array}$ & $\begin{array}{c}\text { Metodologia/procedimentos - } \\
\text { Coleta de dados }\end{array}$ & $\begin{array}{c}\text { Metodologia/procedimentos - } \\
\text { Análises }\end{array}$ & $\begin{array}{c}\text { Sujeitos } \\
\text { coadjuvantes }\end{array}$ \\
\hline $\begin{array}{l}\text { CASTRO } \\
(2004)\end{array}$ & $\begin{array}{l}\text { - Diário de campo } \\
\text { - Registros dos alunos } \\
\text { - Gravações em áudio } \\
\text { - Tarefas investigativas }\end{array}$ & $\begin{array}{c}\text { - Informações e análises sob a } \\
\text { forma de narrativas reflexivas } \\
\text { escritas e, como apoio, } \\
\text { um grupo colaborativo de } \\
\text { professores de matemática }\end{array}$ & $\begin{array}{c}\text { - Grupo de } \\
\text { Sábado } \\
\text { - Turmas da } 8^{a} \text { - } \\
\text { série (9ํano EF) }\end{array}$ \\
\hline $\begin{array}{l}\text { QUISBERT } \\
(2015)\end{array}$ & $\begin{array}{l}\text { - Diário de bordo } \\
\text { - Relatórios dos instrumentos } \\
\text { (questionários) aplicados no } \\
\text { projeto no qual a pesquisa } \\
\text { estava inserida. }\end{array}$ & $\begin{array}{c}\text { - Análise documental e } \\
\text { descritiva }\end{array}$ & - Grupo focal \\
\hline
\end{tabular}

Fonte: Elaborado pelos autores a partir do corpus da pesquisa.

AÇÃO COLABORATIVA E PESQUISAS DA PRÓPRIA PRÁTICA: UM DEVIR PARA ALÉM DA SIMPLES COOPERAÇÃO

Para as discussões, partimos do pressuposto de que a prática do professor é, em toda a sua dimensão, uma prática social e, como tantas outras, é uma forma de intervir no meio social. A partir disso, podemos apreender que essa ação docente não se constitui isoladamente, mas num contexto de um trabalho coletivo que pode ser cooperativo e/ou colaborativo.

Nesse ponto, cabe esclarecer, conforme Boavida e Ponte (2002), que a cooperação consiste numa fase de trabalho coletivo que ainda não é, efetivamente, colaborativo, pois apesar de realizarem ações conjuntas e de comum acordo, parte do grupo não tem autonomia para tomar decisões sobre essas ações. Diferentemente, na colaboração, todos trabalham em apoio mútuo, visando aos objetivos comuns que são negociados no coletivo do grupo.

Nessa perspectiva de trabalho conjunto e colaborativo, a liderança é compartilhada, assumindo corresponsabilidades na condução das ações. Esclarecidas essas questões, podemos afirmar que, em nosso estudo, a partir dos participantes e seus envolvimentos, as pesquisas mapeadas evidenciaram investigações mais voltadas para o diálogo da prática do professor pesquisador: 1) com os processos metodológicos de ensino, tendo como interlocutores os seus alunos; 2) com o professor regente e sua sala de aula; ou 3) com a sua própria prática, tendo como interlocutores os processos 
de ensino-aprendizagem de sua sala de aula, sinalizando para um trabalho de porte muito mais cooperativo do que colaborativo, não refletindo o que apontam as literaturas que discutem esse tipo de investigação, tais como: Boavida e Ponte (2002), Cochran-Smith (2003), Ponte e Serrazina (2003), Ponte (2004, 2008), Fiorentini (2013), entre outros, que exaltam os processos de colaboração no desenvolvimento das pesquisas da própria prática. Esses estudos têm apontado a colaboração como um dos aspectos mais importantes na constituição de uma nova cultura profissional dos professores.

Neste aspecto, evidenciamos que, entre as 16 pesquisas mapeadas, apenas Castro (2004) e Quisbert (2015) tiveram, no desenvolvimento da pesquisa, a intervenção de um grupo como interlocutor no processo de investigação da própria prática, porém, cabe ressaltar que Castro (2004) é a que mais se aproxima das proposições dos autores supracitados.

Castro (2004) realizou a investigação da sua própria prática num contexto de sala de aula, privilegiando as aulas investigativas e as atividades/tarefas exploratório-investigativas. Asua pesquisa apontou que as aulas investigativas supõem um maior envolvimento dos alunos com as tarefas investigativas de matemática e, ao mesmo tempo, exigem um professor muito mais preparado para mediar essas tarefas junto ao aluno. Nesse sentido, a autora ressalta a relevância que o processo colaborativo, mediado pelo grupo de estudos no viés colaborativo, o Grupo de Sábado, teve em sua investigação:

Durante esse processo, foi fundamental a mediação colaborativa do Grupo de Sábado e minha própria investigação sobre a prática. Tudo isso, interligado, contribuiu para que eu ressignificasse a teoria relativa às investigações matemáticas em sala de aula, apropriandome, assim, efetivamente, dela, produzindo novos saberes docentes. Em meio a todo esse processo fui reconfigurando, aos poucos, minha prática pedagógica. Identifiquei, então, as primeiras mudanças... Percebi-me propondo aos alunos situações mais abertas, desafiandoos a formularem conjecturas, colocá-las em discussão, argumentar em defesa delas, comprová-las ou refutá-las. Além disso, notei em mim o movimento de procurar apoiar as ideias dos alunos, arbitrar conflitos, valorizando e dinamizando as interações professoraluno e aluno-aluno (CASTRO, 2004, p. 182).

Numa configuração metodológica, Castro (2004) utilizou os seguintes instrumentos para a coleta de dados: diário de campo; registros dos alunos; gravações em áudio e os protocolos das tarefas investigativas. Nos procedimentos de análise, a pesquisadora partiu das narrativas reflexivas escritas, tendo como interlocutor dessas reflexões e legitimador do processo de investigação de sua própria prática um grupo colaborativo, composto por professores, pesquisadores e alunos de matemática, o chamado Grupo de Sábado (GdS). 
Ao referir-se ao Grupo de Sábado, Castro (2004, p. 9) escreve que:

Este grupo, constituído por professores universitários, mestrandos e doutorandos em Educação Matemática e, principalmente, por professores de Matemática do Ensino Fundamental e Médio, procura, através de trabalhos colaborativos, desencadear um processo cíclico de reflexão e ação em nossas próprias práticas pedagógicas. Esse processo remete, principalmente, a três momentos de reflexão: antes, durante e posterior à ação.

Ao detalhar sobre esses três momentos de reflexão possibilitados pelo $\mathrm{GdS}$, a autora explicita que a reflexão antes da ação acontecia, na maioria das vezes, durante o planejamento, problematização e discussão de uma ação a ser desenvolvida em sala de aula. Afirma que era uma oportunidade de considerar as múltiplas variáveis que poderiam influir na ação, e era também o momento no qual buscavam colocar-se no papel do aluno. 0 "refletir durante a ação" era a tomada de decisão diante de dilemas. Era quando precisavam rever as estratégias no curso da ação, decidir como intervir nos rumos do trabalho e como mediar a produção de significados que estava ocorrendo junto ao GdS ou à sala de aula. Quanto ao terceiro momento, "reflexão posterior à ação", é possível perceber uma potencialidade deste, principalmente quando se trata de uma investigação dessa natureza, pois essa reflexão possibilita ao professor pesquisador revisitar a sua própria prática e, se for o caso, reformulá-la, conforme a autora declara:

O momento de reflexão posterior à ação tem se mostrado extremamente rico à medida que nos permite analisar nossa própria prática com um certo distanciamento. Outro ponto importante a ser destacado é o fato de nossa prática ser apresentada para ser analisada também pelos integrantes do Grupo de Sábado. Lá são lançados sobre nosso trabalho outros olhares, são reveladas nuances, expostas falhas, descobertas riquezas. $O$ trabalho é avaliado para que aprendamos com ele e possamos replanejá-lo (CASTRO, 2004, p. 10).

Outro aspecto que nos chamou a atenção no desenvolvimento da pesquisa de Castro (2004) foi a utilização das narrativas reflexivas em seus procedimentos de análises. É possível verificar a importância que a pesquisadora atribui a essa potente ferramenta, permitindo-lhe lançar um olhar distanciado sobre si mesmo e sobre a sua prática, possibilitando analisar o próprio desempenho profissional, como aponta: 
As narrativas não representavam apenas uma forma de apresentação e de sistematização dos acontecimentos. Ao produzi-las, ocorria um primeiro afastamento e estranhamento entre eu e os fatos. Esse estranhamento dava origem a crises, pois, através da escrita, refletia sobre minha prática e tomava conhecimento das limitações de meu trabalho, de meus saberes e de minhas próprias ideias. Assim, ao refletir por escrito, criava condições

para que outras reflexões e elaborações ocorressem a partir desses escritos. Esperava, com isso, produzir condições para análises mais profundas e conclusões mais consistentes

A autora explica que, nas narrativas, as vozes dos integrantes do GdS nem sempre ficaram explícitas e, muitas vezes, podem estar entrelaçadas com a sua própria voz, pois conta que, por ser também integrante do grupo, é possível que tenha se apropriado das reflexões como um todo, ficando até mesmo impossível distinguir as reflexões que elaborou sozinha das que foram elaboradas de modo compartilhado no grupo.

A pesquisa de Quisbert (2015) foi desenvolvida a partir de um projeto maior que tinha como objetivo analisar os impactos de documentos curriculares e, especialmente, dos Cadernos de Apoio e Aprendizagem de Matemática (CAA), elaborados pela Secretaria Municipal de Educação (SME-SP), na prática e no desenvolvimento profissional de professores, a fim de apontar ajustes necessários a serem feitos para potencializar a aprendizagem dos alunos.

A partir da pesquisa da própria prática, a pesquisadora buscou responder à seguinte questão: "Que aspectos apontam as reflexões da professora pesquisadora sobre o uso de materiais didáticos institucionais de matemática em seu trabalho de sala de aula?” (QUISBERT, 2015, p. 17). Dessa forma, a referida pesquisa centrou-se na prática da professora pesquisadora, quando utilizou materiais didáticos institucionais, analisando as suas ações a partir de descrições feitas em seus relatórios, diário de bordo, nos questionários instrumentos de pesquisas do projeto financiado pela Fundação de Amparo à Pesquisa do Estado de São Paulo (Fapesp) - e nos instrumentos do grupo focal, em que os professores/pesquisadores e o pesquisador/moderador planejavam e discutiam o trabalho a ser realizado nas salas de aula com 0 uso dos CAA.

Quanto aos instrumentos de sistematização dos dados da pesquisa, a utilização do diário de bordo pela pesquisadora foi essencial. A pesquisadora justifica essa utilização por considerá-lo, a partir de seus referenciais teóricos, um dos instrumentos mais ricos de coleta de informações, em especial para sua investigação, pois se trata de um relatório descritivo e de um instrumento de autorreflexão e avaliação. Teve como objetivo registrar, de maneira detalhada 
e sistematizada, os acontecimentos, as rotinas, as discussões e reflexões que contribuíram para o processo de análise das ocorrências observadas.

De acordo com Quisbert (2015, p. 58):

O diário de bordo foi organizado conforme as orientações das professoras responsáveis pelo projeto Dra. Edda Curi e Dra. Célia Carolino Pires. O roteiro de observação era combinado com o grupo e o pesquisador colaborador a cada 15 dias e servia de subsídios para as discussões coletivas e as sínteses e intervenções dos pesquisadores colaboradores para o próximo encontro. Foram realizados 18 encontros de 4 horas aos sábados na Universidade Cruzeiro do Sul.

Sobre a metodologia de grupo focal, Quisbert (2015, p. 44) aponta que:

[...] o objetivo central do grupo focal é identificar percepções, sentimentos, atitudes e ideias dos participantes a respeito de um determinado assunto, produto ou atividade. Seus objetivos específicos variam de acordo com a abordagem de pesquisa. [...] A discussão é conduzida por um moderador que utiliza dinâmicas de grupo a fim de compreender os sentimentos expressos pelos participantes. [...] A discussão do grupo focal deve acontecer numa atmosfera agradável e informal, capaz de colocar seus participantes à vontade para expor ideias, sentimentos, necessidades e opiniões.

No que diz respeito ao grupo em que desenvolveu a sua investigação, reconhecemos que não foi um grupo dito colaborativo, como conceituamos a partir do nosso referencial teórico, mas assumidamente um grupo focal. No entanto, a partir do que Quisbert (2015) conceitua sobre o referido grupo, evidenciamos algumas aproximações ao que estamos considerando como ações colaborativas, como a reflexão, o respeito mútuo e o compartilhamento de conhecimentos. A pesquisadora descreve como eram essas interações:

A discussão do grupo focal deve acontecer numa atmosfera agradável e informal, capaz de colocar seus participantes à vontade para expor ideias, sentimentos, necessidades e opiniões. [...] A dinâmica e a interação do grupo tornam-se parte integrante da técnica, pois os participantes, engajados na discussão, dirigem seus comentários aos outros participantes, ao invés de interagirem apenas com o moderador (QUISBERT, 2015, p. 45).

Assim, partindo das configurações apresentadas nas pesquisas de Castro (2004) e Quisbert (2015), e seguindo o movimento de sistematização, no viés de síntese interpretativa que os estudos bibliográficos possibilitamnos, podemos inferir que uma das possíveis configurações metodológicas da pesquisa da própria prática aliada às ações colaborativas, objetivo deste estudo, constituir-se-iam da seguinte forma: desenvolvimento nos moldes da pesquisa-ação colaborativa mediada pelas tendências da educação matemática, especialmente a metodologia de investigação matemática, possibilitando as aulas investigativas e atividades/tarefas do tipo 
exploratório-investigativas, tendo como principais instrumentos de coleta de dados o diário de campo/caderno de campo, o diário de bordo e os registros em áudio e/ou vídeo das situações de ensino-aprendizagem nos contextos de sala de aula. No tocante às análises, foram realizadas preferencialmente por elaboração de narrativas e análises documental e descritiva.

\section{ALGUMAS CONSIDERAÇÕES}

Na busca por uma configuração metodológica das pesquisas que investigam a própria prática, mediadas por ações colaborativas, realizamos o mapeamento das produções acadêmicas voltadas para o tema no período entre 2011 e 2016, observando as metodologias e os procedimentos metodológicos assumidos pelos autores. Desse modo, foi possível observar uma variedade de metodologias, instrumentos de coleta de dados e procedimentos de análises presentes nas pesquisas. Os estudos bibliográficos permitiramnos evidenciar aproximações como a utilização dos pressupostos do grupo colaborativo na pesquisa de Castro (2004) por meio do GdS e na pesquisa de Quisbert (2015) pelo grupo focal.

Quanto às demais pesquisas do nosso rol - também desenvolvidas no viés da pesquisa da própria prática, mas que não foram abordadas em nossa análise por não atenderem ao nosso objetivo neste artigo -, julgamos relevante pontuar uma evidência significativa para a área da educação matemática. Trata-se da presença marcante nessas pesquisas das tendências metodológicas da educação matemática: a investigação matemática, a resolução de problemas, a tecnologia, a matemática financeira; a modelagem matemática e, ainda, a etnomatemática, notadamente como atividades promotoras de aprendizagens significativas, observadas tanto na prática do professor investigador como no desenvolvimento dos sujeitos coadjuvantes da investigação. Ademais, em relação a essas pesquisas, outra evidência dos nossos fichamentos foram os sujeitos envolvidos, considerados interlocutores nesses processos de investigação da própria prática. Há de se destacar a presença majoritária de alunos dos ensinos fundamental II e médio e, em caso mais específico, de um segundo professor, ou seja, além do professor investigador que está desenvolvendo a pesquisa, também o professor regente da sala. Notamos ainda a frequente ocorrência de atividades realizadas em sala de aula, vinculada a um conteúdo específico e ao desenvolvimento das atividades investigativas propostas em forma de projetos. 
Porém, no tocante às duas pesquisas analisadas, destacamos a importância do "Grupo" como interlocutor da investigação, destacada no discurso de Castro (2004).

Nós, do Grupo de Sábado, estudamos, planejamos e discutimos ações a serem desenvolvidas em sala de aula, privilegiando uma prática reflexiva. Temos consciência da importância desse movimento no processo de nos constituirmos professores de Matemática e entendemos que tudo isso pode ser uma alternativa de formação continuada para outros professores.

Essa importância também é salientada no discurso de Quisbert (2015), que relata que a partir dos relatórios e das discussões realizadas no grupo focal, o planejamento era refeito e o professor reelaborava as adaptações necessárias à sua atuação em sala de aula. "Nesse sentido, o grupo Focal e a escola passaram a serem espaços privilegiados de formação" (QUISBERT, 2015, p. 128).

Em síntese, esses dois trabalhos corroboram, como ponto positivo da pesquisa, as relações estabelecidas com outros profissionais por meio de grupos de pesquisas no qual se inseriram. Identificaram que a colaboração e a parceria dos grupos são estratégias fundamentais para lidar com problemas ou dificuldades que não conseguiriam resolver individualmente, como afirma Quisbert (2015, p. 128): “A possibilidade de dividir academicamente minhas reflexões é um novo caminho formativo que se abre para a minha formação".

Em suma, cabe evidenciar que o processo de pesquisar a própria prática não é um fim em si mesmo. É perceptível que a cada movimento surge uma infinidade de indícios que nos possibilitam explorar novos contextos que incidem sobre a "própria prática", cheia de interferências e relações e interrelações, como os eus, os outros eus, os outros e os espaços, com os quais os sujeitos conectam-se e relacionam-se. E, conforme já descortinamos, é uma atividade complexa.

Destarte, parafraseando Ponte (2004), reforçamos que pesquisar a própria prática não se trata de transformar professores em pesquisadores profissionais, mas convidá-los a usar a pesquisa como uma forma, entre outras, de lidar com as complexidades que a própria prática impõe-lhes ou, em adjacências interpretativas, presenteia-os, visto que as possibilidades são as ferramentas para a concretude da realidade, toda e qualquer realidade. 


\section{Collaboration: An Action to Legitimize Research by Mathematics Teachers on Their Own Practice}

Abstract: This article aims to summarize the theoretical and methodological framework of dissertations and theses produced between 2001 and 2016 which involve research of own practice and include collaboration as one of the actions that legitimize the investigation process. Our methodological approach has characteristics of collaborative research and relies on of bibliographic studies. By analyzing data, we found that although the term "own practice" appears in research, few studies actually use collaboration as an action to legitimize the process.

Keywords: Mathematics education. Own practice research. Collaboration. 


\section{Colaboración: una acción para legitimar las investigaciones de la propia práctica de los profesores de matemáticas}

Resumen: Este artículo tiene como objetivo presentar una síntesis de la estructura teórico-metodológica que fundamenta las disertaciones y las tesis producidas entre 2001 y 2016, relacionadas con la investigación de la propia práctica, en las cuales la colaboración se constituye como una de las acciones para legitimar el proceso investigativo. El caminar metodológico tiene características de la investigación colaborativa, con el auxilio de los estudios bibliográficos. El análisis de los datos reveló que, aunque el término "propia práctica» esté presente en las investigaciones, aún hay pocas producciones en las que las acciones para legitimar el proceso se configuren como colaboración.

Palabras clave: Educación matemática. Investigación de la propia práctica. Colaboración. 


\section{REFERÊNCIAS}

ABREU, Maria das Graças dos Santos. Uma investigação sobre a prática pedagógica: refletindo sobre a investigação nas aulas de matemática. 2008. 193 f. Dissertação (Mestrado em Educação)-Universidade Federal de São Carlos, São Carlos, 2008.

ALARCÃO, Isabel (Org.). Escola reflexiva e nova racionalidade. Porto Alegre: Artmed, 2001.

ALMEIDA, Adriana Correa. Trabalhando matemática financeira em uma sala de aula do ensino médio da escola pública. 2004. 124 f. Dissertação (Mestrado em Educação)- Universidade Estadual de Campinas, Campinas, 2004.

ARAGÓN, Dionara Teresinha da Rosa. Formação continuada de professores de matemática: espaço de possibilidades para produzir formas de resistência docente. 2009. 111 f. Dissertação (Mestrado em Educação)- Faculdade de Educação, Universidade Federal do Rio Grande do Sul, Porto Alegre, 2009.

BIAJONE, Jefferson. Trabalho de projetos: possibilidades e desafios na formação estatística do pedagogo. 2006. 249 f. Dissertação (Mestrado em Educação)-Universidade Estadual de Campinas, Campinas, 2006.

BITENCOURT, Karliúza Fonseca. Educação matemática por projetos: perspectivas e prática pedagógica no contexto escolar. 2007. 220 f. Dissertação (Mestrado em Educação) - Faculdade de Educação, Universidade Federal do Rio Grande do Sul, Porto Alegre, 2007.

BOAVIDA, Ana Maria; PONTE, João Pedro. Investigação colaborativa: potencialidades e problemas. In: GTI (Org). Reflectir e investigar sobre a prática profissional. Lisboa: APM, 2002. p. 43-55.

CASTRO, Juliana Facanali. Um estudo sobre a própria prática em um contexto de aulas investigativas de matemática. 2004. 197 f. Dissertação (Mestrado em Educação)-Universidade Estadual de Campinas, Campinas, 2004.

CHARLOT, Bernard. Da relação com o saber às práticas educativas. 1. ed. São Paulo: Cortez, 2014.

COCHRAN-SMITH, Marilyn. Learning and unlearning: The education of teacher education. Teaching and Teacher Education, v. 19, n. 1, p. 5-28, 2003.

DAY, Christopher. Desenvolvimento profissional de professores: os desafios 
da aprendizagem permanente. Porto, Portugal: Editora Porto, 2001.

FELIX, Thiago Francisco. Pesquisando a melhoria de aulas de matemática segundo a proposta curricular do estado de São Paulo, com a metodologia da pesquisa de aula (Lesson Study). 2010. 153 f. Dissertação (Mestrado em Ensino de Ciências Exatas)-Universidade Federal de São Carlos, São Carlos, 2010.

FERNANDES, Fernando Luís Pereira. Iniciação e práticas de letramento algébrico em aulas exploratório-investigativas. 2011. 140 f. Dissertação (Mestrado em Educação)-Universidade Estadual de Campinas, Campinas, 2011.

FERREIRA, Maria Salonilde; IBIAPINA, Ivana Maria Lopes de Melo. A pesquisa colaborativa como espaço formativo. In: MAGALHÃES, M. C. C.; FIDALGO, S. S. (Org.). Questões de métodos e de linguagem na formação docente. Campinas: Mercado de Letras, 2011. p. 119-140.

FERREIRA, Norma Sandra de Almeida. As pesquisas denominadas "Estado da Arte”. Educação \& Sociedade, Campinas, v. 23, n. 79, p. 257-272, ago. 2002.

FIORENTINI, Dario. Aprendizagem profissional e participação em comunidade investigativa. In: ENCONTRO NACIONAL DE EDUCAÇÃO MATEMÁTICA, 11., 2013, Curitiba. Anais... Curitiba: Sociedade Brasileira de Educação Matemática, 2013. p. 1-15.

; PASSOS, Cármen Lúcia Brancaglion; LIMA, Rosana Catarina Rodrigues (Org.). Mapeamento da pesquisa acadêmica brasileira sobre o professor que ensina matemática: período 2001-2012. Campinas: FE-Unicamp, E-book, 2016. Disponível em: 〈https://www.fe.unicamp.br/pf-fe/pagina_basica/58/ebook-mapeamento-pesquisa-pem.pdf $>$.

FONSECA, Rosana Carla. Matemática se aprende brincando?! Jogos eletrônicos como uma possibilidade de ensino. 2007, 151 p. Dissertação (Mestrado em Educação)- Faculdade de Educação e de Letras, Universidade Metodista de São Paulo, São Bernardo do Campo, 2007.

GTI, Grupo de Trabalho sobre Investigação (Org.). Refletir e investigar sobre a prática profissional. Lisboa: APM, 2002.

IBIAPINA, Ivana Maria Lopes de Melo. Pesquisa colaborativa: investigação, formação e produção de conhecimentos. Brasília: Líber Livro Editora, 2008. . Pesquisar e formar colaborativamente: desafios e perspectivas. In: 
BALDI, E. M. B.; FERREIRA, M. S.; PAIVA, M. (Org.) Epistemologia das ciências da educação. Natal: EDUFRN, 2009. p. 209-226.

LIBERALI, Fernanda Coelho. Por um sujeito livre que não teme; faz escolhas. In: SCHETTINI, R.; DAMIANOVIC, M. C.; HAWI, M.; ZSUNDY, P. T. C (Org.). Vygotsky: uma revisita no início do século XXI. São Paulo: Andross, 2009. p. 233-254.

LIMA, Claudia Neves do Monte Freitas. Investigação da própria prática docente utilizando tarefas exploratório-investigativas em um ambiente de comunicação de ideias matemáticas no ensino médio. 2006. 204 f. Dissertação (Mestrado em Educação)-Universidade São Francisco, São Paulo, 2006.

LIMA, Cristina Maria Peixoto Berbert. Trajetórias no chão da escola: uma pedagoga nas trilhas da educação matemática com professores de séries iniciais. 2010. 142 f. Dissertação (Mestrado em Educação)-Universidade Federal do Paraná, Curitiba, 2010.

LOPES, Maria da Penha. Desvelando práticas bem-sucedidas de uma professora de matemática. 2007, 172 f. Tese (Doutorado em Conhecimento e Inclusão Social)- Faculdade de Educação, Universidade Federal de Minas Gerais, Belo Horizonte, 2007.

MACHADO JUNIOR, Arthur Gonçalves. Modelagem matemática no ensinoaprendizagem: ação e resultados. 2005. 143 f. Dissertação (Mestrado em Educação em Ciências e em Matemática)-Universidade Federal do Pará, Belém, 2005.

MAGALHÃES, Maria Cecília Camargo. O método para Vygotsky: a zona proximal de desenvolvimento como zona de colaboração e criticidade criativas. In: SCHETTINI, R. H. et al (Org.). Vygotsky: uma (re)visita no século XXI. São Paulo: Andross, 2009. p. 53-78.

MESQUITA, Flávio Nazareno Araujo. As dinâmicas praxeológicas e cognitivas e a construção do conhecimento didático do professor de matemática. 2011. 106 f. Dissertação (Mestrado em Educação em Ciências e em Matemática)Universidade Federal do Pará, Belém, 2011.

MILANI, Camille Bordin Botke. O desenvolvimento do pensamento teórico de uma professora principiante de matemática no processo educativo. 2016. 164 f. Dissertação (Mestrado em Educação em Ciências e em Matemática)Universidade Federal do Paraná, Curitiba, 2016. 
PONTE, João Pedro. Da formação ao desenvolvimento profissional. In: ENCONTRO NACIONAL DE PROFESSORES DE MATEMÁTICA, 1998, Guimarães. Actas... Lisboa: APM, 1998. p. 27-44.

. Investigar a nossa própria prática. In: GTI (Org.). Refletir e investigar sobre a prática profissional. Lisboa: APM, 2002. p. 5-28.

- Investigar a nossa própria prática: uma estratégia de formação e de construção do conhecimento profissional. Lisboa: APM, 2008. p. 153-180.

- Pesquisar para compreender e transformar a nossa própria prática. Educar, Curitiba: Editora UFPR, n. 24, p. 37-66, 2004.

; SERRAZINA, Lurdes. Professores e formadores investigam a sua própria prática: o papel da colaboração. Zetetiké, v. 11, n. 20, p. 51-84, jul./ ago. 2003.

QUISBERT, Susan Quiles. Relações de uma professora pesquisadora de sua própria prática com o uso de materiais didáticos institucionais de matemática. 2015. 131 f. Dissertação (Mestrado em Ensino de Ciências e Matemática)Universidade Cruzeiro do Sul, São Paulo, 2015.

VOSGERAU, Dilmeire Sant'Anna Ramos; ROMANOWSKI, Joana Paulin. P. Estudos de revisão: implicações conceituais e metodológicas. Revista Diálogo Educacional, Curitiba, v. 14, n. 41, p. 165-189, jan./abr. 2014.

SOBRE AS AUTORAS

Patrícia Sandalo Pereira é doutora em Educação Matemática pela Unesp - Rio Claro/SP. Atualmente é diretora do Instituto de Matemática (Inma) e docente nos cursos de Licenciatura em Matemática, Programa de Pós-graduação em Educação Matemática (Mestrado e Doutorado) e no Doutorado em Ensino de Ciências da Universidade Federal de Mato Grosso do Sul (UFMS). E-mail: sandalo.patricia13@gmail.com

Edinalva Teixeira da Cruz Sakai é doutoranda e mestre em Educação Matemática pela UFMS. Atua como docente do curso de Licenciatura em Educação do Campo da Universidade Federal de Mato Grosso do Sul (UFMS). E-mail: edisakai@hotmail.com

Kely Fabrícia Pereira Nogueira é doutoranda e mestre em Educação Matemática pela UFMS. Atualmente é bolsista pela Fundação de Apoio ao Desenvolvimento 
do Ensino, Ciência e Tecnologia do Estado de Mato Grosso do Sul (Fundect).

E-mail: kelyn230@gmail.com

Recebido em: abril de 2018

Aceito em: maio de 2018 